\title{
High Vocational Tourism-based Virtual Simulation Training Center Construction Studies and Practices
}

\author{
A Case Study of Chengdu Polytechnic \\ Hong Guangying 1, a , Lai Bin ${ }^{2, b, *}$ \\ ${ }^{1}$ Chengdu Polytechnic, Chengdu, Sichuan, China \\ ${ }^{2}$ Chengdu Polytechnic, Chengdu, Sichuan, China \\ a675150418@qq.com, b2220285867@qq.com \\ *Hong Guangying (Corresponding author)
}

\begin{abstract}
Keywords: High Vocational Education; Tourism Specialty; Virtual Simulation; Training Center
\end{abstract}
\begin{abstract}
In line with the new demands put forth for cultivation of professional talents based on the industrial development, virtual simulation training system for tourism specialty is built with the aid of simulation techniques such as the virtual reality so as to solve a series of bottleneck problems caused due to the immobility and inaccessibility of tourism resources, non-replicability of large-scale tourist activities and tourist safety accident which can hardly be experienced in tourism teaching practices, aiming for high vocational tourism students' practical ability improvement and integrated innovation ability enhancement.
\end{abstract}

\section{Introduction}

In the wake of the pervasive development of information technology in economy and community life, our production patterns, lifestyles and ways of learning have been undergoing profound changes. New business modes and technologies such as the "Internet+", "Tourism+", smart tourism and region-based tourism spring up constantly, which put forward higher demands for integrated development, innovation and creativity and information technology application ability of tourist practitioners, and in response, tourism vocational educational teaching mode is in need of reform and innovation to adapt to the market demands on the talents of tourism. The paper, by summarizing the studies and practices performed by Virtual Simulation Training Center of Chengdu Polytechnic, is intended to explore the integration of modern information technology development and application achievements with tourism practical training conditions so as to build a high vocational tourism-based virtual simulation training center in an innovative way, improve the tourism vocational practice and teaching levels and training benefit and facilitate the growth and development of high vocational tourism specialty.

\section{Construction necessity of high vocational tourism-based virtual simulation training center}

\subsection{Problems to be overcome for high vocational tourism-based practical teaching in an urgent manner}

The booming new tourism business patterns have set new requirements for talents of tourism in terms of professional capabilities and skills. It is a new task or new subject in the practical teaching activities to cultivate students' job adaptability and integration and innovation abilities. Through analysis, the prominent problems are identified in current tourism specialty practical teaching, which are manifested in following ways: (1) extensive distribution and immobility of tourism resources and insufficient tourism resources live experience and comparison of teachers and students, which weaken the practical teaching effect; (2) limited to the business nature of company and job post setting, job positions rotation can hardly be performed in practical teaching activities, which make the teaching and training objectives difficult to be achieved; (3) all large-scale and comprehensive tourist events are carried out in real-time and irreversible fashion which would lead 
to uncertainty of training program, resulting in poor continuity of practical teaching program and internship and susceptibility to the market environment; (4) rapidly renewing tourism specialty experimental resources and high cost for its building and maintenance make the school in short of teaching expenditure and site area; (5) resources and materials for innovative and creative product design training typically have wide range of types and kinds which are less in quantity and disposable and are hard to be sourced from market. In actual creative production process, such resources and materials are not sufficiently supplied but lavishly consumed with high cost; (6) high-risk tourist safety activity or activity to be performed in extreme environment cannot be implemented as such activities are in need of reliable and safety-oriented training programs.

\subsection{Virtual simulation training center built by relying on information technology for overcoming bottleneck problems and practical teaching quality improvement}

With the application and development of information technology in the field of education, virtual simulation practical teaching has become a new mean and approach to overcome difficulties and problems in practical teaching. Over the last few years, the virtual simulation practical teaching has been largely promoted and performed in industry and medicine sectors, having offered a reliable training solution for those teaching programs troubled by inaccessible and irreversible conditions. Inspired by the Higher Vocational Education Innovative Development Action Plan (Year 2015-2018), higher vocational institutes are encouraged to set up virtual simulation training centers to complement conventional practice and training programs and improve the practical teaching level.

By relying on the modern virtual reality information technology, practical teaching resources and training programs are to be developed and tourism resources-oriented and multicultural immersive, experiential and comparative learning are to be carried out grounded upon the tourist activity process, the working environment and the virtual simulation teaching environment so as to integrate the real production training and simulated training with virtual simulation training, which is practicable and necessary to break through current practical teaching bottlenecks and improve the teaching level.

On the strength of this, Chengdu Polytechnic had been engaged in exploring the construction and application of tourism virtual simulation training center since 2011.

\section{Virtual simulation training center construction practice}

\subsection{Background}

The rapid development of tourism puts forward new demands for integration and innovative development of high vocational tourism-based talents; in contrast, the majority of students of tourism in our school have no or few experiences in tourism with vague or uncertain recognition and understanding of tourism and less knowledge in new tourist business patterns. The problem is that the practical teaching pattern of the school currently is unable to bridge the differences between the talent demand and student's status. Through analytical investigation, Chengdu Polytechnic commenced the construction of the high vocational tourism-based virtual simulation training center in 2011 to build a "virtual simulation + simulated practical training + job post practice" practical teaching system in order to meet the demands for higher vocational tourism teaching method innovation and development, overcome current practical teaching bottleneck problems and improve the professional teaching quality and students' competitiveness in an even better fashion.

\subsection{Ideas}

As per the requirement of "cultivating the cultural creativity-oriented talents of tourism", emphasis will be placed on setting up the virtual simulation training resources, virtual practical training platform construction and team building to establish a virtual reality combined tourism specialty practical teaching system integrated with resource system, platform and teaching management team, 
aiming to create a resources-sharing organic whole to continuously serve the practical teaching with guaranteed teaching quality.

\subsection{Content}

\subsubsection{Practical teaching resources development}

A R\&D team will be set up with the support of the tourism company, software development company, and teaching backbone staff, aiming to break down the segments in tourism in line with the main route of tourism spending, tourist service and management before re-integrating those to form the tourism specialty teaching content. Core curriculum resources, teaching training programs and training materials are to be developed through school-business cooperation. 6 tourism specialty virtual simulation teaching resources systems have been developed and integrated, 7 resources sharing courses have been introduced, 12 "cultural creativity immersive experiencing" virtual simulation training programs have been developed, 13 "cultural creativity and planning" virtual simulation training programs have been developed and 1 tourism big data training system has been completed independently by the school.

\subsubsection{Practical teaching platform construction}

On the basis of virtuality-reality combined practical teaching system construction scheme, the virtual simulation practical teaching platform is bound to be optimized from three aspects: (1) to complete training center network infrastructure construction and network information security system construction, to renovate 5 tourism cultural innovation and startup project workshops and 25 virtual simulation training rooms; (2) to develop high vocational tourism-based virtual simulation teaching training system through school-business cooperation for the 25 training programs; (3) to integrate the systems with educational administration system, CRP, students management system, teaching staff management system for the sake of resources interconnectivity and intercommunication, building a teaching- training-management integrated platform.

\subsubsection{Teaching staff building}

The teaching staff building level straightly acts on the construction quality and operating efficiency of the virtual simulation training center. Thus, the director's responsibility system under the college leadership has been determined since the beginning of the construction, in which team building and system building will be carried out simultaneously to expedite the project construction. Moreover, the practical training program $R \& D$ team backed by teaching elites, enterprise specialists and software developers and the training teaching team supported by full-time teachers and training mentors are assembled to be in charge of training program and associated resources development and training and teaching performance; the training center operation and maintenance team backed by technical professionals is assembled to take charge of the center's daily teaching management and equipment operation and maintenance works. To ensure the orderly running of the center in a reliable manner, the center attaches importance to system building and has established 13 management rules and regulations successively to regulate center affairs ranging from project $R \& D$, teacher promotion, teaching performance appraisal, and training management for the purpose of developing an operation supporting mechanism for the center.

\subsection{Features and outcomes}

\subsubsection{Innovation of features}

For the "four integrations" and building a virtual simulation teaching system, the school keeps exploring and practicing by focusing on cultivation of cultural creativity-oriented talents of tourism to realize the multi-channel and multi-type integrated teaching resources, multi-dimension and multi-pattern integrated teaching scenarios, multi-mode and multi-form integrated teaching approaches and multi-function and multi-system integrated teaching management. The school is meant to build a virtuality-reality combined and mutually complemented practical teaching system to put the simulated practice and internship job which are hard to be performed in tourism industrial chain into practice so as to minimize the resource consumption and cultivate students' creative design capacity. 
For the "two changes", unbounded professional cooperation and integrated development, the virtual simulation teaching programs and virtual simulation teaching system will be developed in line with the "catering+ accommodation+ transportation + travel +shopping + entertainment" tourist industry chain. The training room building mode of "by specialty" will be changed into "by project" in order to gather relevant teaching staff and resources, carry out teaching and research works collaboratively and break disciplinary barriers and the traditional teaching pattern of "by specialty" will be changed as well. Through the two changes, the disciplinary boundary gets out of focus so that unbounded cooperation among industry, academy and research institute can be carried out for integrated development, seeking for a new high vocational tourism-based practical teaching pattern in response to the region-based tourism business.

\subsubsection{Operating efficiency}

Since the kickoff of the center construction, teachers have been proactively carrying out project development and transformation, performing teaching reform studies and promoting tourism information teaching reform by taking advantage of the center, having been awardedmultiple provincial-level and municipal-level teaching achievement prizes and software copyrights. Furthermore, the center, apart from undertaking the practical teaching works for over 2000 students, is also open to other member schools within the region via Chengdu Tourism Vocational Teaching Group Platform and undertakes training programs for students from other schools. Its construction quality and operating efficiency are thought highly by the industry and enterprises as well as the college and industrial experts. Besides remarkable grades and scores obtained in professional skills competitions at all levels, our students are also favored and praised by the industry and companies.

\section{Summary}

The construction of the center has attracted more and more attentions from vocational colleges. So far, the construction and application of the center is still at the exploratory stage and the following two tasks need to be promoted to give full swing to its role in practical teaching.

\subsection{Optimization and integration, system development, enriching practical teaching program}

To analyze and evaluate the operating status of current teaching resources management system, optimize and integrate the existing resources in response to the new demands for specialty building and development; to continue carrying out the training standard development and associated teaching materials formulation and optimize training management performance appraisal procedure; to improve the practical teaching resource system based on specialty-based practical teaching, project development and creative design demands so as to promote the transformation of training program research achievements from classroom teaching to physical practice and improve the operating efficiency and stability of the system.

\subsection{Further improvement of training center system building}

To further improve the resources construction and maintain long-term incentive mechanism, improve teachers' information teaching skill level and promote the reform and innovation of teaching patterns. The training center's teaching management mode will be improved to stimulate teachers' enthusiasms in participating in practical training teaching and motivate students' initiative in training programs so as to improve the center's service efficiency and give full swing to its realistic role in talent cultivation and community service. Moreover, the center's sharing mechanism building will be strengthened to get academic, local and enterprises resources integrated for center-based radius sharing pattern promotion.

\section{Acknowledgement}

This paper is one of the phase achievements of "high vocational tourism-based virtual simulation training center construction" project at earlier stage. We hereby would like to extend sincere 
gratitude to all project members for the time and painstaking efforts they have been taken in going this far with us!

\section{References}

[1] Zhang Liping, Exploration on Tourist Information Technology Skills Cultivation for Students in Tourism Major in Higher Vocational College in the Internet+ Context [J]. China after School Education, 2017, (09): 155-156. [2017-10-08].

[2] Ma Lihua, "Reflections on Higher Vocational Teaching Patterns in the Internet+ Context [J]. Education Modernization, 2016, 3(29): 174-175. [2017-10-08]. DOI: 10.16541/j.cnki.2095-8420.2016.29.080

[3] Feng Shanshan, Exploratory Study on Virtual Simulation Practical Training Platform Construction [J]. Wireless Internet Technology, 2016,(10):108-110. [2017-10-08].

[4] Teng Daoming, Vocational Education Beware of Generalization of Virtual Simulation Practical Training [J]. Vocational Education (Midmonth periodical), 2016, (04):12-14+24. [2017-10-08].

[5] Zhao Qinping, Overview of Virtual Reality [J]. Science in China (Vol. F: Information Science), 2009, 39 (01):2-46. [2017-10-08]. 